\title{
Early outcomes after isolated aortic valve replacement with rapid deployment aortic valve
}

\author{
Thorsten C. W. Wahlers, MD, PhD, ${ }^{a}$ Axel Haverich, MD, ${ }^{b}$ Michael A. Borger, MD, PhD, ${ }^{c}$ \\ Malakh Shrestha, MBBS, PhD, ${ }^{\mathrm{b}}$ Alfred A. Kocher, MD, ${ }^{\mathrm{d}}$ Thomas Walther, MD, PhD, ${ }^{\mathrm{e}}$ Matthias Roth, MD, ${ }^{\mathrm{e}}$ \\ Martin Misfeld, MD, ${ }^{c}$ Friedrich W. Mohr, MD, PhD, ${ }^{c}$ Joerg Kempfert, MD, ${ }^{e}$ Pascal M. Dohmen, MD, PhD, ${ }^{f}$ \\ Christoph Schmitz, MD, ${ }^{\mathrm{g}}$ Parwis Rahmanian, MD, ${ }^{\mathrm{a}}$ Dominik Wiedemann, MD, ${ }^{\mathrm{d}}$ Francis G. Duhay, MD, ${ }^{\mathrm{h}}$ \\ and Günther Laufer, $\mathrm{MD}^{\mathrm{d}}$
}

\begin{abstract}
Objective: Minimal access aortic valve replacement is associated with favorable clinical outcomes; however, several meta-analyses have reported significantly longer crossclamp times compared with a full sternotomy. We examined the procedural and early safety outcomes after isolated rapid deployment aortic valve replacement by surgical approach in patients enrolled in the Surgical Treatment of Aortic Stenosis With a Next Generation Surgical Aortic Valve trial.
\end{abstract}

Methods: The Surgical Treatment of Aortic Stenosis With a Next Generation Surgical Aortic Valve trial was a prospective, multicenter, single-arm study, with successful implants in 287 patients with aortic valve stenosis who underwent rapid deployment aortic valve replacement using the EDWARDS INTUITY Valve System (Edwards Lifesciences, Irvine, Calif). Patients were evaluated perioperatively for procedural times and technical success rates; at discharge, for hospital length of stay; and, at 30 days, for early adverse events.

Results: A total of 158 patients underwent isolated aortic valve replacement through a full sternotomy $(\mathrm{n}=71)$, upper hemisternotomy $(\mathrm{n}=77)$, or right anterior thoracotomy $(n=10)$. Mean age at baseline was $75.7 \pm 7.2$ years. Mean aortic crossclamp and cardiopulmonary bypass times (minutes) were similar for full sternotomy and upper hemisternotomy, $43.5 \pm 32.5 / 71.6 \pm 41.8$ and $43.1 \pm 13.1 / 69.6 \pm 19.1$, respectively, and significantly longer for right anterior thoracotomy, $88.3 \pm 18.6 /$ $122.2 \pm 22.1(P<.000)$. Early adverse event rates were similar, and in-hospital mortality rates were low regardless of surgical approach.

Conclusions: These data suggest that isolated rapid deployment aortic valve replacement through an upper hemisternotomy can lead to shorter crossclamp times than has been reported historically in the literature. This may facilitate minimal access aortic valve replacement by eliminating the issue of prolonged crossclamp times. Further, low in-hospital mortality and new permanent pacemaker implant rates were observed regardless of surgical approach. (J Thorac Cardiovasc Surg 2016;151:1639-47)

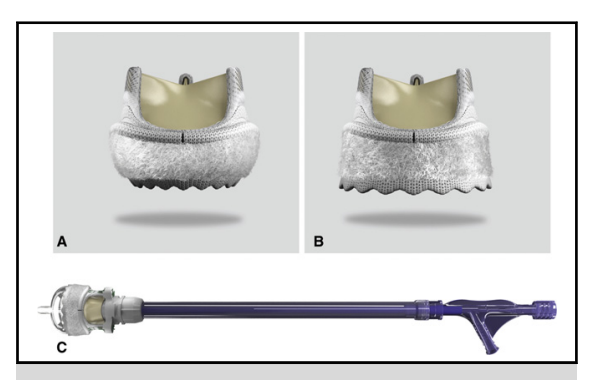

EDWARDS INTUITY valve (Edwards Lifesciences, Irvine, Calif).

\section{Central Message}

RDAVR may facilitate the use of minimal access surgical techniques.

\section{Perspective}

RDAVR may facilitate the use of minimal access surgical techniques by reducing the longer aortic crossclamp times often incurred. We present the results of patients in the TRITON trial undergoing isolated AVR using RDAVR through a full sternotomy or minimal access surgery.

See Editorial Commentary page 1648.
Aortic valve replacement (AVR) through the use of a minimal access incision can be performed safely without increased risk of death or major complications and may

\footnotetext{
From the ${ }^{\mathrm{a}}$ Medical University of Cologne, Cologne, ${ }^{\mathrm{b}}$ Medical University of Hannover, Hannover; ${ }^{c}$ Heart Center Leipzig; ${ }^{d}$ Medical University of Vienna, Vienna, Austria; ${ }^{\mathrm{e}}$ Kerckhoff Klinik, Bad Nauheim, ${ }^{\mathrm{f}}$ University of Leipzig, Leipzig, and ${ }^{\mathrm{g}}$ University of Munich, Munich, Germany; and ${ }^{\mathrm{h}}$ Edwards Lifesciences LLC, Irvine, Calif.

This study was sponsored by Edwards Lifesciences LLC.

Read at the 95th Annual Meeting of The American Association for Thoracic Surgery, Seattle, Washington, April 25-29, 2015.
}

provide both cosmetic and clinical benefits for selected patients with aortic valve disease. ${ }^{1}$ It is hypothesized that reduced surgical trauma through maintenance of chest

Received for publication May 22, 2015; revisions received Dec 1, 2015; accepted for publication Dec 24, 2015; available ahead of print Feb 15, 2016.

Address for reprints: Thorsten C. W. Wahlers, MD, PhD, Hospital and Health Center for Heart and Thoracic Surgery, University Clinic, Kerpener Strasse 46, Cologne 50937, Germany (E-mail: thorsten.wahlers@uk-koeln.de).

$0022-5223 / \$ 36.00$

Copyright (C) 2016 by The American Association for Thoracic Surgery

http://dx.doi.org/10.1016/j.jtcvs.2015.12.058 


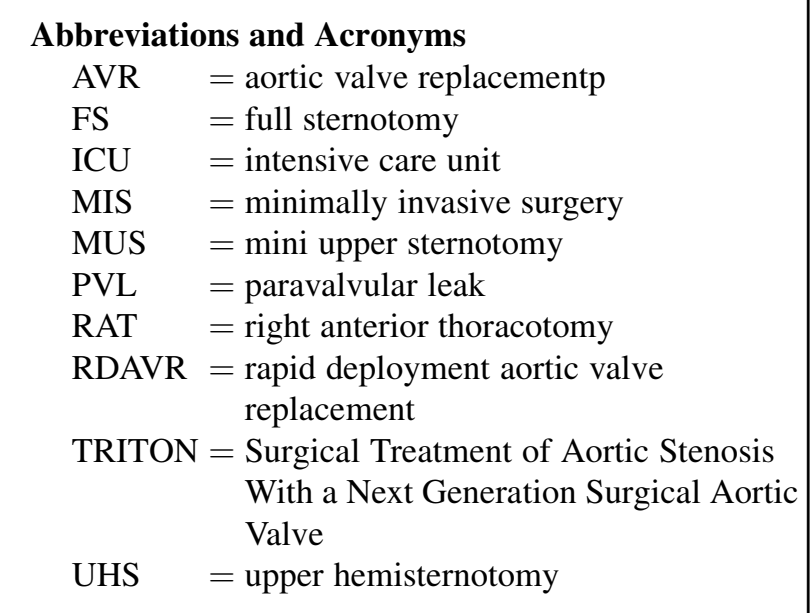

Scanning this QR code will take you to the article title page. To view the AATS 2015 Webcast, see the URL at the end of the article.

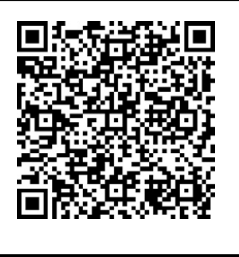

wall integrity leads to decreased postoperative pain and disability, reduced blood loss, shorter ventilation times, and reduced intensive care unit (ICU) and hospital length of stays. ${ }^{2}$ Furthermore, specific patient subsets, such as those with pulmonary dysfunction, may derive further benefit from using a minimal access incision for $\mathrm{AVR}^{3}$

Historically, minimal access incisions for AVR have been associated with longer aortic crossclamp and cardiopulmonary bypass times compared with the standard full sternotomy (FS) approach. Longer periods of myocardial ischemia and exposure to cardiopulmonary bypass may lead to higher morbidity and mortality, particularly in patients requiring concomitant procedures or in higher surgical risk populations. ${ }^{4}$ A new class of bioprosthetic valves that enables rapid deployment aortic valve replacement (RDAVR) may facilitate the use of minimal access incisions by neutralizing the difference in myocardial ischemic time often ascribed to using this approach. ${ }^{5}$ Previously published data have demonstrated the safety, efficacy, and expedited procedural times enabled by RDAVR. ${ }^{6-8}$ Furthermore, the recently published 3-year results of the Surgical Treatment of Aortic Stenosis With a Next Generation Surgical Aortic Valve (TRITON) study have demonstrated low complication rates and excellent hemodynamic performance of the EDWARDS INTUITY valve (Edwards Lifesciences, Irvine, Calif), which was specifically designed to facilitate RDAVR.
The TRITON trial is a prospective, multicenter, singlearm study, with successful implants in 287 patients with aortic valve disease who required elective AVR and underwent RDAVR using the EDWARDS INTUITY Valve System, a balloon-expandable stented trileaflet bovine pericardial bioprosthesis. The surgical incision used was left to the discretion of the operating surgeon. Outcomes from the TRITON study recently have been published demonstrating excellent hemodynamic and safety outcomes with up to 3 years follow-up. ${ }^{7}$ The objective of this study was to compare procedural times, discharge outcomes, technical success rates, and early safety outcomes by surgical approach among patients enrolled in the TRITON trial who underwent isolated RDAVR through an FS, upper hemi-sternotomy (UHS), and right anterior thoracotomy (RAT).

\section{MATERIALS AND METHODS Study Population}

The TRITON Trial (NCT01445171) is a prospective, nonrandomized, single-arm, multicenter trial conducted in 6 European hospitals. The study design and methods have been described by Kocher and associates. ${ }^{9}$ A total of 295 consecutive patients with moderate to severe aortic valve disease requiring elective AVR with or without concomitant coronary artery bypass grafting were enrolled; 287 of these were treated with the EDWARDS INTUITY Valve System (Model 8300A), a stented trileaflet bovine pericardial bioprosthesis with a balloon-expandable, cloth-covered skirt frame at the inflow aspect. A total of 158 of 287 patients underwent isolated RDAVR (Figure 1). The study protocol was reviewed and approved by the Ethics Committee of each participating center, and all patients provided written informed consent.

\section{Rapid Deployment Aortic Valve Replacement}

RDAVR with the EDWARDS INTUITY Valve System (Figure 2) was performed through a minimal access incision (upper hemisternotomy [UHS] or RAT) or FS, as previously described by Kocher and associates, ${ }^{9}$ according to surgeon preference. ${ }^{10}$ After a standard aortotomy, the diseased aortic valve leaflets were excised and annular calcium was debrided using conventional surgical techniques. Three equidistant guiding sutures were placed through the nadir of each aortic cusp and then through the corresponding position of the valve sewing ring. By using the specialized delivery system, the valve was lowered onto the annulus using the 3 guiding sutures. After the valve was seated, the balloon catheter was expanded to rapidly deploy the valve. After deployment, the delivery system was removed, guiding sutures were tied, and the aortotomy was closed in routine fashion.

\section{End Points}

Clinical follow-up data were collected per protocol at baseline, discharge, and 3 and 12 months postoperatively. For the purposes of this study, patients were evaluated perioperatively for procedural times and procedural and technical success rates; at discharge for hospital length of stay, ICU length of stay, intermediate care length of stay, and in-hospital mortality; and at 30 days for early adverse event rates. The adverse events were adjudicated as per The Society of Thoracic Surgeons Guidelines for reporting mortality and morbidity after cardiac valve interventions, ${ }^{10}$ and included all-cause and valve-related mortality, thromboembolic events (stroke, transient ischemic attack, and noncerebral embolic event), study valve thrombosis, major bleeding events, paravalvular leak (PVL), prosthetic valve endocarditis, reoperation for bleeding, and study valve 


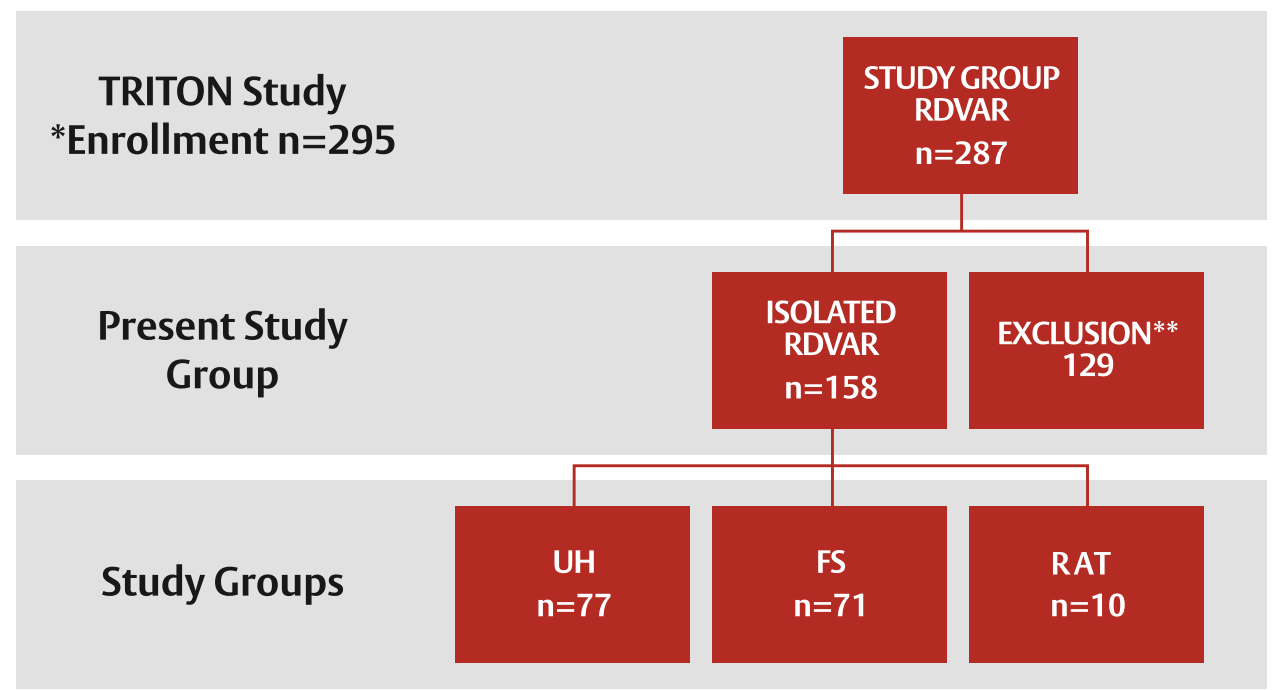

FIGURE 1. Study population. *Eight subjects were excluded because they were not suitable for RDAVR. **Exclusion criteria: concomitant procedures. TRITON, Surgical Treatment of Aortic Stenosis With a Next Generation Surgical Aortic Valve; RDVAR, rapid deployment aortic valve replacement; $U H$, upper hemisternotomy; FS, full sternotomy; RAT, right anterior thoracotomy.

explant. All-cause mortality includes all deaths from any cause after a valve intervention. Valve-related mortality is any death caused by structural valve deterioration, nonstructural dysfunction, valve thrombosis, embolism, bleeding event, or operated valve endocarditis; death related to reintervention on the operated valve; or sudden, unexplained death. Embolism is defined as any embolic event that occurs in the absence of infection after the immediate perioperative period. Stroke is a prolonged ( $>72$ hours) or permanent neurologic deficit that is usually associated with abnormal results of magnetic resonance imaging or computed tomography scans. Patients with minimal, atypical, or protean symptoms that lead to radiographic imaging demonstrating an acute ischemic event are considered to have sustained a stroke. Transient ischemic attack is characterized by fully reversible symptoms of short duration. If radiographic imaging demonstrates an acute central neurologic lesion ("cerebral infarction with transient symptoms"), however, such patients are reclassified as having sustained a stroke. A noncerebral embolic event is an embolus documented operatively, at autopsy, or clinically that produces signs or symptoms due to complete or partial obstruction of a peripheral artery. (excluding myocardial infarction, except one caused by a coronary embolus as detected by operation, autopsy, or clinical imaging). Emboli consisting of nonthrombotic material (eg, atherosclerosis, myxoma) are not counted. Valve thrombosis is defined as a blood clot on the valve not associated with infection, causing dysfunction of the heart valve substitute. Major bleeding event is defined as any episode of major internal or external bleeding that causes death, hospitalization, or permanent injury (eg, vision loss) or necessitates transfusion of 3 or
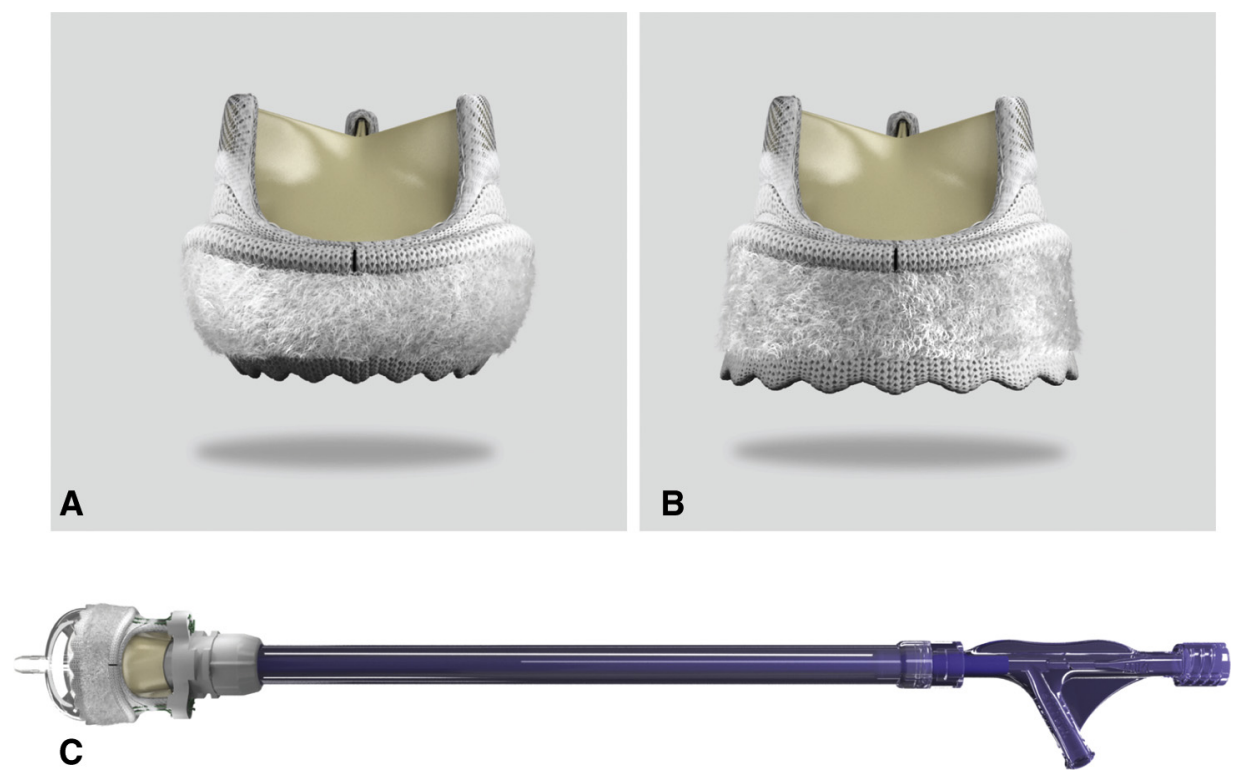

FIGURE 2. The EDWARDS INTUITY valve (Edwards Lifesciences, Irvine, Calif). The subannular skirt frame in precrimped configuration (A), deployed configuration (B), and complete valve deployment system (C). 
more units of red blood cells. Major PVL is defined as a PVL, exclusive of that associated with thrombosis or infection, that (1) leads to intervention or reoperation (with or without symptoms), (2) graded moderate or greater (with or without symptoms and with or without intervention/ reoperation), or (3) results in death or that is moderately sized or greater when diagnosed by autopsy. Prosthetic valve endocarditis is infection of the endocardium, which is the inner lining of the heart muscle and heart valves, usually caused by bacteria or fungus. Reoperation is any surgical or percutaneous interventional catheter procedure that repairs, otherwise alters or adjusts, or replaces a previously implanted prosthesis or repaired valve.

Technical success was defined as delivery and deployment of the study valve within 2 attempts and leaving the operating room with the study valve in place.

Procedural success was defined as technical success plus the absence of complications requiring device reoperation, new permanent pacemaker implantation (in a patient with baseline normal sinus rhythm and no conduction disturbance), or death within 10 days or discharge, whichever is first.

\section{Data Management}

As the study sponsor, Edwards Lifesciences managed the collection and monitoring of data; however, the surgeon investigators assumed primary responsibility for the interpretation of the data.

\section{Statistical Analysis}

Continuous variables are summarized as mean and standard deviation, and categoric variables are expressed as percentages. Complications are summarized for the early ( $\leq 30$ days of the index procedure) period. Early rates are calculated as the number of events divided by the total number of patients. Statistical inferences comparing continuous variables were made using generalized linear models, and comparisons of categoric variables were made using Pearson's chi-square test (or Fisher exact test when expected cell frequencies were too low). Two-sided tests were used, and a type I error significance level of .05 was considered. For all pairwise comparisons, multiple comparison adjustment was conducted using the method of Scheffé. All data are based on a data extract date of June 17, 2014.

\section{RESULTS \\ Baseline Patient and Echocardiographic Characteristics}

Baseline patient and echocardiographic characteristics are presented in Table 1 . Of the 287 patients who underwent RDAVR with an EDWARDS INTUITY valve, 158 underwent isolated AVR, which represents the patient population described in the current analysis. The surgical approach was left to the discretion of the surgeon; thus, distributions of surgical approaches are as follows: FS $(\mathrm{n}=71)$, UHS $(\mathrm{n}=77)$, and RAT $(\mathrm{n}=10)$. Mean age at baseline was $75.7 \pm 7.2$ years, mean logistic European System for Cardiac Operative Risk Evaluation was $8.2 \pm 6.6$, and $60.5 \%, 57.1 \%$, and $20.0 \%$ of patients were in New York Heart Association class III/IV for FS, UHS, and RAT, respectively.

\section{Early Safety Outcomes}

Early safety outcome rates were similar in all 3 groups (Table 2). Two early mortalities were recorded among patients receiving implants: One patient in the FS cohort
TABLE 1. Demographics and baseline characteristics by surgical approach

\begin{tabular}{|c|c|c|c|}
\hline Variable & $\begin{array}{c}\text { FS } \\
\mathbf{N}=\mathbf{7 1}\end{array}$ & $\begin{array}{c}\text { UHS } \\
\mathbf{N}=77\end{array}$ & $\begin{array}{c}\text { RAT } \\
\mathbf{N}=\mathbf{1 0}\end{array}$ \\
\hline Age (y) & Mean \pm SD & Mean \pm SD & Mean \pm SD \\
\hline Age, $y$ & $75.7 \pm 6.8$ & $75.6 \pm 6.6$ & $75.3 \pm 13.5$ \\
\hline Gender/sex & $\%(\mathrm{n} / \mathrm{N})$ & $\%(\mathrm{n} / \mathrm{N})$ & $\%(\mathrm{n} / \mathrm{N})$ \\
\hline Female & $49.3 \%(35 / 71)$ & $50.6 \%(39 / 77)$ & $60.0 \%(6 / 10)$ \\
\hline Male & $50.7 \%(36 / 71)$ & $49.4 \%(38 / 77)$ & $40.0 \%(4 / 10)$ \\
\hline Risk score & Mean \pm SD & Mean \pm SD & Mean \pm SD \\
\hline $\begin{array}{l}\text { Logistic } \\
\quad \text { euroSCORE, \% }\end{array}$ & $8.0 \pm 6.4$ & $7.9 \pm 4.9$ & $12.0 \pm 14.8$ \\
\hline NYHA & $\%(\mathrm{n} / \mathrm{N})$ & $\%(\mathrm{n} / \mathrm{N})$ & $\%(\mathrm{n} / \mathrm{N})$ \\
\hline Class I & $5.6 \%(4 / 71)$ & $5.2 \%(4 / 77)$ & $0.0 \%(0 / 10)$ \\
\hline Class II & $33.8 \%(24 / 71)$ & $37.7 \%(29 / 77)$ & $80.0 \%(8 / 10)$ \\
\hline Class III & $54.9 \%(39 / 71)$ & $53.2 \%(41 / 77)$ & $20.0 \%(2 / 10)$ \\
\hline Class IV & $5.6 \%(4 / 71)$ & $3.9 \%(3 / 77)$ & $0.0 \%(0 / 10)$ \\
\hline $\begin{array}{c}\text { Echocardiographic } \\
\text { variables }\end{array}$ & Mean \pm SD & Mean \pm SD & Mean \pm SD \\
\hline $\begin{array}{l}\text { Aortic annulus } \\
\text { diameter, } \mathrm{mm}\end{array}$ & $56: 23.1 \pm 2.2$ & $65: 23.1 \pm 2.1$ & $9: 23.0 \pm 2.2$ \\
\hline $\begin{array}{l}\text { Body mass index, } \\
\mathrm{kg} / \mathrm{m}^{2}\end{array}$ & $71: 28.7 \pm 4.2$ & $77: 27.8 \pm 4.4$ & $10: 25.7 \pm 3.4$ \\
\hline $\begin{array}{l}\text { Body surface } \\
\text { area, } \mathrm{m}^{2}\end{array}$ & $71: 2.0 \pm 0.2$ & $77: 1.9 \pm 0.2$ & $10: 1.9 \pm 0.2$ \\
\hline $\begin{array}{l}\text { Index annulus } \\
\text { diameter, } \mathrm{mm} / \mathrm{m}^{2}\end{array}$ & $56: 12.0 \pm 1.2$ & $65: 12.2 \pm 1.3$ & $9: 12.3 \pm 1.7$ \\
\hline LVEF, \% & $48: 62.7 \pm 10.9$ & $52: 58.2 \pm 12.9$ & $8: 59.3 \pm 7.9$ \\
\hline $\begin{array}{l}\text { Comorbidities/ } \\
\text { medical history }\end{array}$ & $\%(\mathrm{n} / \mathrm{N})$ & $\%(\mathrm{n} / \mathrm{N})$ & $\%(\mathrm{n} / \mathrm{N})$ \\
\hline $\begin{array}{l}\text { COPD/pulmonary } \\
\text { disease }\end{array}$ & $9.9 \%(7 / 71)$ & $7.8 \%(6 / 77)$ & $20.0 \%(2 / 10)$ \\
\hline Diabetes & $9.9 \%(7 / 71)$ & $11.7 \%(9 / 77)$ & $10.0 \%(1 / 10)$ \\
\hline Prior cardiac surgery & $14.1 \%(10 / 71)$ & $15.6 \%(12 / 77)$ & $20.0 \%(2 / 10)$ \\
\hline Renal failure/dialysis & $11.3 \%(8 / 71)$ & $18.2 \%(14 / 77)$ & $10.0 \%(1 / 10)$ \\
\hline $\begin{array}{l}\text { Systemic } \\
\text { hypertension }\end{array}$ & $80.3 \%(57 / 71)$ & $84.4 \%(65 / 77)$ & $70.0 \%(7 / 10)$ \\
\hline
\end{tabular}

became asystolic after cardiogenic shock; after multiple resuscitation attempts, the study valve was explanted because of suspected damage; after extracorporeal membrane oxygenation and intra-aortic balloon pump implantation, the patient ultimately had cardiac arrest. A second patient, in the UHS cohort, had a myocardial infarction. Bleeding events requiring reoperation occurred in 11 patients: 5 patients $(7.0 \%)$ who underwent an FS and 6 patients $(7.8 \%)$ who underwent a UHS; all patients recovered. One patient in the FS cohort who underwent reoperation for bleeding required explantation of the study valve. Other reasons for study valve-related explants were the aforementioned death $(\mathrm{n}=1)$ and major PVL resulting in hemolysis $(n=1)$ in the FS and UHS cohorts, respectively. One patient in the UHS group had major 
TABLE 2. Early (<30 days) safety outcomes by surgical approach

\begin{tabular}{|c|c|c|c|c|c|c|}
\hline Event & FS $\%(\mathbf{n} / \mathbf{N})$ & $\begin{array}{c}\text { MUS } \\
\%(n / N) \\
\end{array}$ & $\begin{array}{c}\text { Right } \\
\text { thoracotomy } \\
\%(\mathbf{n} / \mathbf{N}) \\
\end{array}$ & $\begin{array}{c}\text { Overall MIS } \\
\text { (MUS + RAT) } \\
\%(\mathbf{n} / \mathbf{N}) \\
\end{array}$ & $\begin{array}{c}\text { All } \\
\text { approaches } \\
\%(\mathbf{n} / \mathbf{N}) \\
\end{array}$ & $\begin{array}{c}\text { FS vs } \\
\text { UHS vs } \\
\text { RAT } \\
\end{array}$ \\
\hline All-cause mortality & $1.4(1 / 71)$ & $1.3(1 / 77)$ & $0.0(0 / 10)$ & $1.1(1 / 87)$ & $1.3(2 / 158)$ & $0.99 *$ \\
\hline Study valve-related mortality & $1.4(1 / 71)$ & $1.3(1 / 77)$ & $0.0(0 / 10)$ & $1.1(1 / 87)$ & $1.3(2 / 158)$ & $0.99 *$ \\
\hline Reoperation for bleeding & $7.0(5 / 71)$ & $7.8(6 / 77)$ & $0.0(0 / 10)$ & $6.9(6 / 87)$ & $7.0(11 / 158)$ & $0.99 *$ \\
\hline Renal failure/dysfunction & $2.8(2 / 71)$ & $9.1(7 / 77)$ & $0.0(0 / 10)$ & $8.0(7 / 87)$ & $5.7(9 / 158)$ & $0.29 *$ \\
\hline Thromboembolic event & $2.8(2 / 71)$ & $7.8(6 / 77)$ & $0.0(0 / 10)$ & $6.9(6 / 87)$ & $5.1(8 / 158)$ & $0.39^{*}$ \\
\hline Deep sternal wound infection & $1.4(1 / 71)$ & $7.8(6 / 77)$ & $0.0(0 / 10)$ & $6.9(6 / 87)$ & $4.4(7 / 158)$ & $0.20 *$ \\
\hline Respiratory dysfunction & $2.8(2 / 71)$ & $3.9(3 / 77)$ & $0.0(0 / 10)$ & $3.4(3 / 87)$ & $3.2(5 / 158)$ & $0.99 *$ \\
\hline Major bleeding Events & $11.3(8 / 71)$ & $6.5(5 / 77)$ & $0.0(0 / 10)$ & $5.7(5 / 87)$ & $8.2(13 / 158)$ & 0.35 \\
\hline Study valve-related explant & $2.8(2 / 71)$ & $1.3(1 / 77)$ & $0.0(0 / 10)$ & $1.1(1 / 87)$ & $1.9(3 / 158)$ & $0.68 *$ \\
\hline Perivalvular leak requiring surgical intervention & $0.0(0 / 71)$ & $1.3(1 / 77)$ & $0.0(0 / 10)$ & $1.1(1 / 87)$ & $0.6(1 / 158)$ & $0.99 *$ \\
\hline Pacemaker implants, total & $5.6(4 / 71)$ & $5.2(4 / 77)$ & $0.0(0 / 10)$ & $4.6(4 / 87)$ & $5.1(8 / 158)$ & $0.99 *$ \\
\hline Valve-related pacemaker implants & $4.2(3 / 71)$ & $2.6(2 / 77)$ & $0.0(0 / 10)$ & $2.3(2 / 87)$ & $3.2(5 / 158)$ & $0.76^{*}$ \\
\hline
\end{tabular}

In cases in which expected cell counts are 5 or greater, $P$ values are based on Pearson's chi-square test. Otherwise, the Fisher exact test is used. Summary statistics are taken from safety results and reproduced here. FS, Full sternotomy; MUS, mini upper sternotomy; MIS, minimally invasive surgery; RAT, right anterior thoracotomy; UHS, upper hemisternotomy. *Indicates use of Fisher exact test.

PVL requiring surgical intervention and study valve explantation. There were no early safety events in the RAT group (Table 2).

\section{Procedural Outcomes}

Device technical success was achieved in 97.2\% (71/73), $97.4 \%$ (77/79), and 100\% (10/10) of patients for FS, UHS, and RAT, respectively. Procedural success was achieved in $93.1 \%$ (68/73), 94.9\% (75/79), and 100.0\% (10/10) of patients, respectively.

Of the 71 patients who underwent an FS, study valve size distributions were as follows: $19 \mathrm{~mm}$ in 2 patients $(2.8 \%)$, $21 \mathrm{~mm}$ in 17 patients $(23.9 \%), 23 \mathrm{~mm}$ in 24 patients $(33.8 \%), 25 \mathrm{~mm}$ in 24 patients $(33.8 \%)$, and $27 \mathrm{~mm}$ in 4 patients $(5.6 \%)$. Seventy-seven patients underwent RDAVR through an upper hemi-sternotomy with 2 patients $(2.6 \%)$ receiving a $19-\mathrm{mm}$ valve, 27 patients $(35.1 \%)$ receiving a $21-\mathrm{mm}$ valve, 22 patients $(28.6 \%)$ receiving a $23-\mathrm{mm}$ valve, 23 patients $(29.9 \%)$ receiving a $25-\mathrm{mm}$ valve, and 3 patients $(3.9 \%)$ receiving a $27-\mathrm{mm}$ valve. AVR via RAT was performed in 10 patients with $21-\mathrm{mm}$ valves implanted in 2 patients $(20 \%), 23-\mathrm{mm}$ valves implanted in 4 patients $(40 \%), 25-\mathrm{mm}$ valves implanted in 3 patients $(30 \%)$, and a $27-\mathrm{mm}$ valve implanted in 1 patient $(10 \%)$.

Four patients who underwent isolated AVR ultimately received a commercial valve: 2 in the FS cohort and 2 in the UHS cohort. Reasons for conversion to control valve in the FS group were 1 case in which the implanting surgeon was unable to place the study valve in the aortic annulus, 1 case in which the appropriate size study valve was not available for implant (FS), 1 case of PVL (noncoronary cusp) after implantation of the study valve (mini upper sternotomy [MUS]), and 1 case in which the appropriate size study valve was not available for implant (FS).

Mean aortic crossclamp and cardiopulmonary bypass times (minutes) were similar for FS and UHS, $43.5 \pm 32.5 / 71.6 \pm 41.8$ and $43.1 \pm 13.1 / 69.6 \pm 19.1$, respectively, and, significantly longer for RAT, $88.3 \pm 18.6 / 122.2 \pm 22.1(P<.0001$ for both RAT vs UHS, and RAT vs FS) (Table 3 ).

TABLE 3. Procedural outcomes

\begin{tabular}{|c|c|c|c|c|c|c|c|c|c|}
\hline Variable & $\begin{array}{c}\text { FS n: } \\
\text { mean } \pm \text { SD } \\
(\text { min, max }) \\
\text { median }\end{array}$ & $\begin{array}{c}\text { MUS n: } \\
\text { mean } \pm \text { SD } \\
(\text { min, max) } \\
\text { median }\end{array}$ & $\begin{array}{l}\text { Right thoracotomy } \\
\text { n: mean } \pm \text { SD } \\
(\text { min, max }) \\
\text { median }\end{array}$ & $\begin{array}{c}\text { Overall MIS } \\
(\text { MUS + RAT) n: } \\
\text { mean } \pm \text { SD } \\
(\text { min, max }) \\
\text { median }\end{array}$ & $\begin{array}{c}\text { All approaches } \\
\text { n: mean } \pm \text { SD } \\
(\text { min, max }) \\
\text { median }\end{array}$ & $\begin{array}{c}\boldsymbol{P} \\
\text { value }^{*}\end{array}$ & $\begin{array}{c}P \text { value } \\
\text { FS vs } \\
\text { MIS } \dagger\end{array}$ & $\begin{array}{c}P \text { value } \\
\text { FS vs } \\
\text { RAT }^{\dagger}\end{array}$ & $\begin{array}{c}P \text { value } \\
\text { MIS vs } \\
\text { RAT }^{\dagger}\end{array}$ \\
\hline $\begin{array}{l}\text { CPB time } \\
\text { (min) }\end{array}$ & $\begin{aligned} 71: & 71.6 \pm 41.8 \\
& (39.0,366.0) 63.0\end{aligned}$ & $\begin{array}{l}77: 69.6 \pm 19.1 \\
\quad(40.0,138.0) 68.0\end{array}$ & $\begin{array}{l}10: 122.2 \pm 22.1 \\
\quad(97.0,161.0) 116.0\end{array}$ & $\begin{array}{l}87: 75.7 \pm 25.6 \\
\quad(40.0,161.0) 70.0\end{array}$ & $\begin{aligned} 158: & 73.9 \pm 33.8 \\
& (39.0,366.0) 66.5\end{aligned}$ & 1 & 7 & 1 & 1 \\
\hline $\begin{array}{l}\text { Crossclamp } \\
\text { time (min) }\end{array}$ & $\begin{aligned} 71: & 43.5 \pm 32.5 \\
& (13.0,293.0) 37.0\end{aligned}$ & $\begin{array}{l}77: 43.1 \pm 13.1 \\
\quad(23.0,107.0) 40.0\end{array}$ & $\begin{array}{l}10: 88.3 \pm 18.6 \\
\quad(64.0,117.0) 82.5\end{array}$ & $\begin{aligned} 87: & 48.3 \pm 20.0 \\
& (23.0,117.0) 41.0\end{aligned}$ & $\begin{array}{l}\text { 158: } 46.1 \pm 26.4 \\
\quad(13.0,293.0) 40.0\end{array}$ & $<.0001$ & .9930 & $<.0001$ & $<.0001$ \\
\hline $\begin{array}{l}\text { Skin-to-skin } \\
\text { time }(\mathrm{min})\end{array}$ & $\begin{array}{l}70: 158.5 \pm 53.2 \\
\quad(92.0,455.0) 148.5\end{array}$ & $\begin{array}{l}77: 146.2 \pm 32.4 \\
\quad(79.0,246.0) 140.0\end{array}$ & $\begin{array}{l}10: 244.2 \pm 22.8 \\
\quad(210.0,285.0) 243.0\end{array}$ & $\begin{array}{l}87: 157.5 \pm 44.4 \\
\quad(79.0,285.0) 143.0\end{array}$ & $\begin{array}{l}157: 158.0 \pm 48.3 \\
\quad(79.0,455.0) 145.0\end{array}$ & $<.0001$ & .2203 & $<.0001$ & $<.0001$ \\
\hline
\end{tabular}

$F S$, Full sternotomy; $S D$, standard deviation; $M U S$, mini upper sternotomy; $M I S$, minimally invasive surgery; $R A T$, right anterior thoracotomy; $C P B$, cardiopulmonary bypass. ${ }^{*} P$ value from Generalized Linear Model, testing overall differences between surgical approach. $\dagger P$ value from pairwise comparisons adjusted for multiple comparisons using Scheffe's method. 
TABLE 4. Discharge outcomes

\begin{tabular}{|c|c|c|c|c|c|c|}
\hline Variable & $\begin{array}{c}\text { Full sternotomy n: } \\
\text { mean } \pm \text { SD } \\
(\text { min, max }) \\
\text { median }\end{array}$ & $\begin{array}{c}\text { MUS n: } \\
\text { mean } \pm \text { SD } \\
(\min , \max ) \\
\text { median } \\
\end{array}$ & $\begin{array}{c}\text { Right thoracotomy } \mathrm{n} \text { : } \\
\text { mean } \pm \text { SD } \\
(\text { min, max }) \\
\text { median }\end{array}$ & $\begin{array}{c}\text { Overall MIS } \\
(\text { MUS }+ \text { RAT) } \mathbf{n}: \\
\text { mean } \pm \text { SD } \\
(\text { min, max }) \\
\text { median } \\
\end{array}$ & $\begin{array}{c}\text { All Approaches n: } \\
\text { mean } \pm \text { SD } \\
(\text { min, max }) \\
\text { median }\end{array}$ & $\begin{array}{c}P \\
\text { value }\end{array}$ \\
\hline $\begin{array}{l}\text { Hospital length } \\
\text { of stay (d) }\end{array}$ & $\begin{array}{l}69: 11.7 \pm 6.3 \\
\quad(6.0,50.0) 10.0\end{array}$ & $\begin{array}{r}76: 13.1 \pm 10.6 \\
(5.0,89.0) 10.0\end{array}$ & $\begin{array}{l}10: 9.5 \pm 6.7 \\
\quad(5.0,28.0) 7.0\end{array}$ & $\begin{array}{r}86: 12.7 \pm 10.3 \\
\quad(5.0,89.0) 9.0\end{array}$ & $\begin{array}{l}155: 12.3 \pm 8.7 \\
(5.0,89.0) 10.0\end{array}$ & .08 \\
\hline $\begin{array}{l}\text { ICU length } \\
\text { of stay (h) }\end{array}$ & $\begin{array}{c}69: 61.7 \pm 115.4 \\
\quad(0.0,664.0) 24.0\end{array}$ & $\begin{array}{l}76: 59.1 \pm 102.9 \\
(0.0,625.0) 23.0\end{array}$ & $\begin{aligned} 10: & 33.6 \pm 12.4 \\
& (24.0,48.0) 24.0\end{aligned}$ & $\begin{array}{l}\text { 86: } 56.1 \pm 97.0 \\
\quad(0.0,625.0) 24.0\end{array}$ & $\begin{array}{l}155: 58.6 \pm 105.3 \\
\quad(0.0,664.0) 24.0\end{array}$ & .39 \\
\hline $\begin{array}{l}\text { Intermediate care } \\
\text { length of stay }(\mathrm{h})\end{array}$ & $\begin{array}{l}69: 22.3 \pm 45.1 \\
\quad(0.0,192.0) 0.0\end{array}$ & $\begin{array}{l}76: 43.7 \pm 92.8 \\
\quad(0.0,504.0) 0.0\end{array}$ & $\begin{array}{l}10: 19.2 \pm 42.0 \\
\quad(0.0,120.0) 0.0\end{array}$ & $\begin{array}{c}86: 40.9 \pm 88.6 \\
\quad(0.0,504.0) 0.0\end{array}$ & $\begin{array}{c}155: 32.6 \pm 72.9 \\
(0.0,504.0) 0.0\end{array}$ & .01 \\
\hline In-hospital mortality & $2.8 \%(2 / 71)$ & $1.3 \%(1 / 77)$ & $0.0 \%(0 / 10)$ & $1.1 \%(1 / 87)$ & $1.9 \%(3 / 158)$ & .72 \\
\hline
\end{tabular}

\section{Discharge Outcomes}

In-hospital mortality was similar across all 3 groups; $2.8 \%(2 / 71), 1.3 \%(1 / 77)$, and $0.0 \%(0 / 10)$ for FS, UHS, and RAT, respectively $(P>.05$ for FS vs UHS, FS vs RAT, and RAT vs UHS). Hospital, ICU, and intermediate length of stay are presented in Table 3. Hospital length of stay (days) was not different between FS and UHS (11.7 \pm 6.3 and $13.1 \pm 10.6$, respectively) and significantly shorter for RAT, $9.5 \pm 6.7(P<.05$ for RAT vs UHS, and RAT vs FS). ICU and intermediate care length of stay were not different among FS, UHS, and RAT $(P>.05$ for FS vs UHS, FS vs RAT, and RAT vs UHS) (Table 4).

\section{DISCUSSION}

The INTUITY Valve System was uniquely designed to facilitate RDAVR while preserving the excellent hemodynamic performance and durability reported for the Carpentier-Edwards PERIMOUNT family of valves. The objective of the TRITON trial was to evaluate the safety and performance of the INTUITY Valve System. ${ }^{9}$ The main focus of this study is to compare early safety, procedural outcomes, discharge outcomes, and technical success rates by surgical approach in a subgroup of patients enrolled in the TRITON trial who underwent isolated RDAVR. In this reported experience of 158 patients who successfully received implants in 6 centers in Europe, the procedural outcomes of INTUITY demonstrated a technical success rate of $97.2 \%$ for FS, $97.4 \%$ for UHS, and $100 \%$ for RAT. Mean crossclamp/cardiopulmonary bypass times (minutes) were similar for FS and UHS, $43.5 \pm 32.5$ / $71.6 \pm 41.8$ and $43.1 \pm 13.1 / 69.6 \pm 19.1$, respectively, and significantly longer for RAT, $88.3 \pm 18.6 /$ $122.2 \pm 22.1(P<.0001$ for both RAT vs UHS, and RAT vs FS). Early safety outcome rates were equivalent in all 3 groups. There were no early safety events in the RAT group. Early ( $<30$ days) all-cause mortality was low irrespective of surgical approach: $1.4 \%$ (1/71), $1.3 \%$ $(1 / 77)$, and $0.0 \%(0 / 10)$ for FS, UHS, and RAT, respectively. Hospital length of stay (days) was not different between FS and UHS (11.7 \pm 6.3 and $13.1 \pm 10.6$, respectively) and significantly shorter for RAT $(9.5 \pm 6.7)$ $(P<.05$ for RAT vs UHS, and RAT vs FS $)$.

The hybrid design of the EDWARDS INTUITY valve, coupled with a flexible shaft and low-profile delivery system, facilitates minimally invasive AVR and may improve surgical access through smaller incisions. In A Randomized Comparison of the EDWARDS INTUITY Valve System and Commercially Available Aortic Bioprostheses in Subjects Undergoing Surgical Aortic Valve Replacement Using Minimally Invasive Techniques (CADENCE-MIS), a prospective, multicenter, randomized, controlled trial, 2 different surgical strategies were compared: UHS using the EDWARDS INTUITY Valve (minimally invasive surgery [MIS]-RDAVR) versus FS using a conventional surgical valve (FS-AVR). ${ }^{11}$ The results of this study revealed a significant reduction in average crossclamp time for the MIS-RDAVR group compared with the FS-AVR group: 12.7 minutes $(41.3 \pm 20.3$ vs $54.0 \pm 20.3$, respectively; $P<.0001)$. The reduction achieved in myocardial ischemic times in the CADENCE-MIS trial is particularly noteworthy when taking into account the impact of learning curve, because 4 of the 5 hospitals in this trial were using the EDWARDS INTUITY Valve System for the first time. The current study reports similar average crossclamp times through a UHS approach to that reported in CADENCEMIS trial. Moreover, the crossclamp times reported in TRITON and CADENCE-MIS compare favorably to the literature in which several studies have reported average crossclamp times up to 62 to 75 minutes ${ }^{12-14}$ for isolated AVR cases through a UHS approach and 62 to 74 minutes $^{15-18}$ through FS with the use of conventional surgical stented valves. Accordingly, these data suggest that RDAVR using the EDWARDS INTUITY Valve System may facilitate MIS by simplifying the procedure 
TABLE 5. Comparison with Society of Thoracic Surgeons database

Comparison with STS database, crossclamp time implant subjects

\begin{tabular}{lccc}
\hline \multicolumn{1}{c}{ Surgical group } & n: mean \pm SD & STS value & $\boldsymbol{P}$ value \\
\hline Isolated AVR, FS & $71,43.5 \pm 32.5$ & 76.35 & $<.001$ \\
Isolated AVR, MIS & $87,48.3 \pm 20.0$ & 82.98 & $<.001$ \\
\hline
\end{tabular}

Comparison with STS database, bypass time implant subjects

\begin{tabular}{lccc}
\hline \multicolumn{1}{c}{ Surgical group } & n: mean \pm SD & STS value & $\boldsymbol{P}$ value \\
\hline Isolated AVR, FS & $71,71.6 \pm 41.8$ & 104.23 & $<.001$ \\
Isolated AVR, MIS & $87,75.7 \pm 25.6$ & 111.44 & $<.001$ \\
\hline
\end{tabular}

$P$ values are calculated using 1-sample $t$ tests. STS database for the period of July 2011 to December 2012. STS, Society of Thoracic Surgeons; SD, standard deviation; $A V R$, aortic valve replacement; $F S$, full sternotomy; $M I S$, minimally invasive surgery.

steps and neutralizing the concern over longer average periods of myocardial ischemia compared with conventional AVR. Indeed, one may speculate that the benefits of shorter crossclamp times accrued from using the EDWARDS INTUITY Valve System may be more apparent in those surgeons who use longer crossclamp times during conventional AVR.

Aortic valve replacement traditionally is performed through an FS incision; however, with the introduction of minimally invasive AVR, alternative access incisions are slowly gaining acceptance. ${ }^{19,20}$ Many studies demonstrate that AVR through a minimally invasive approach can be done safely with mortality and morbidity rates similar to conventional AVR through FS. ${ }^{21}$ Despite high logistic European System for Cardiac Operative Risk Evaluations at baseline, early mortality rates were low in our cohort and similar in all 3 groups. Early safety outcomes also were similar for all approaches. These findings are similar to those reported in the literature with the use of other sutureless or rapid deployment aortic valves. Dalen and colleagues $^{22}$ reported their experience on 267 consecutive patients who underwent isolated AVR with the use of a self-expanding nitinol rapid deployment aortic valve where $189(70.8 \%)$ of the cases were performed through a ministernotomy and $78(29.2 \%)$ were performed through an FS incision. The study demonstrated similar procedural and early postoperative outcomes for the 2 different surgical access incisions. However, the interpretation of outcomes in both the TRITON trial and the study by Dalen and colleagues $^{22}$ should be viewed with caution because neither study was randomized, included an active comparator group, or was powered to demonstrate significant differences in serious adverse events by surgical approach. Rather, randomized controlled trials with larger cohorts are necessary to draw definitive conclusions on whether RDAVR through minimally invasive access leads to lower rates of mortality or morbidity compared with FS.

Early postoperative permanent pacemaker implantation after isolated AVR ranges between $3.0 \%$ and $8.5 \% .^{23,24}$ Thus far, the relationship between postoperative pacemaker implantation and late mortality has not been fully explored in patients undergoing surgical AVR. However, the question is particularly relevant to transcatheter aortic valve replacement, for which the incidence of postprocedural severe conduction defects is considerably higher. In 2 large series reported by Buellesfeld and colleagues ${ }^{25}(\mathrm{n}=319)$ and De Carlo and colleagues ${ }^{26}(n=275)$, which involved a self-expandable transcatheter aortic valve replacement system, the rate of new permanent pacemaker implantation was $27.8 \%$ and $25.5 \%$, respectively. In our cohort, the rate of new permanent pacemaker implantation was $5.6 \%$ for FS, $5.2 \%$ for UHS, and $0.0 \%$ for RAT, falling well within the expected range for reported values after isolated surgical AVR. These rates also compare favorably with those reported with other RDAVR devices, which use a self-expandable nitinol frame, ranging from $7 \%$ to $17 \%$ in large series of isolated AVRs. ${ }^{6,26-29}$

This study demonstrated INTUITY rapid deployment valves facilitate AVR through all previously described minimally invasive approaches, such as UHS, or through anterior right thoracotomy and FS approaches. Ease of implantation and greater than $90 \%$ technical and procedural success rates are noted to be favorable in comparison with other rapid deployment valves. Early outcome data indicate that the EDWARDS INTUITY prosthesis is safe and reliable in its performance. Previous studies involving minimally invasive AVR reported less bleeding, early recovery time, less pain, and improved cosmesis. ${ }^{30}$ Studies also have reported the costeffectiveness of MIS-AVR with propensity matching and MIS RAT approaches. ${ }^{31,32}$ MIS- RDAVR procedures with novel fast-track focused recovery protocols also may prove to be cost-effective. ${ }^{33}$ Randomized control studies are needed to address this in future.

\section{Study Limitations}

The TRITON trial was a single-arm study without an active comparator group. Thus, it is susceptible to selection and channeling biases. Because "roll-in" cases were not excluded, the outcomes reflect the usually negative impact of the surgeon's learning curve. Furthermore, because the surgical approach was left to the discretion of the surgeon, the use of the RAT technique in 10 patients was attributable to 1 surgeon, which may have influenced the procedural outcomes of this group. During the enrollment phase of the study, considerable emphasis was placed on procedural training and the sharing of best practices among the investigators. Nonetheless, the possibility of performance bias cannot be excluded completely. The clinical end points were objectively defined a priori, and the outcomes were independently determined by a Clinical Events Committee and an Echocardiographic Core Laboratory. Thus, potential detection and measurement biases were mitigated but not completely eliminated. 


\section{CONCLUSIONS}

These data suggest that isolated RDAVR through a UHS can lead to shorter crossclamp times than have been historically reported in the surgical literature (Table 5). This benefit may facilitate minimally invasive AVR by lessening the concern over prolonged crossclamp times, which have been reported in meta-analyses. Further, a low in-hospital mortality, early ( $<30$ days) mortality, and new permanent pacemaker implant rates were observed regardless of surgical approach; however, longer-term follow-up is necessary to further evaluate the benefits of these surgical approaches.

\section{Conflict of Interest Statement}

This study was sponsored by Edwards Lifesciences LLC (Irvine, Calif). T.C.W.W. reports lecture fees from Edwards Lifesciences. A.H. reports a commercial relationship with Edwards Lifesciences, LLC, Thoratec, and Sorin. M.A.B. reports lecture fees from Edwards, St Jude Medical, and Sorin. M.S. reports lecture and consulting fees from Sorin Biomedica and Vascutek Terumo. A.A.K. reports a commercial relationship with Edwards Lifesciences, LLC, Medtronic, and Mesoplast. J.K. reports lecture fees from Edwards Lifesciences, LLC, Symetis, and St Jude Medical. C.S. reports consulting fees from Auto Tissue Berlin $\mathrm{GmbH}$ and BioVentrix. P.R. reports lecture fees from Edwards Lifesciences. F.G.D. reports equity ownership in Edwards Lifesciences. All other authors have nothing to disclose with regard to commercial support.

You can watch a Webcast of this AATS meeting presentation by going to: http://webcast.aats.org/2015/Video/ Tuesday/04-28-15_6B_0740_Wahlers.mp4.

The authors thank Nusrath Sultana, MD, of Medical Affairs at Edwards Lifesciences, LLC, for assistance in the development of this report. Axel Haverich, MD, PhD, is the principal investigator of the TRITON trial.

\section{References}

1. Brown ML, McKellar SH, Sundt TM, Schaff HV. Ministernotomy versus conventional sternotomy for aortic valve replacement: a systematic review and meta-analysis. J Thorac Cardiovasc Surg. 2009;137:670-9.e5.

2. Machler HE, Bergmann P, Anelli-Monti M, Dacar D, Rehak P, Knez I, et al. Minimally invasive versus conventional aortic valve operations: a prospective study in 120 patients. Ann Thorac Surg. 1999;67:1001-5.

3. Albacker TB, Blackstone EH, Williams SJ, Gillinov AM, Navia JL, Roselli EE, et al. Should less-invasive aortic valve replacement be avoided in patients with pulmonary dysfunction? J Thorac Cardiovasc Surg. 2014;147:355-61.e5.

4. Bidar E, Maesen B, Nieman F, Verheule S, Schotten U, Maessen JG. A prospective randomized controlled trial on the incidence and predictors of late-phase postoperative atrial fibrillation up to 30 days and the preventive value of biatrial pacing. Heart Rhythm. 2014;11:1156-62.

5. Gilmanov D, Miceli A, Ferrarini M, Farneti P, Murzi M, Solinas M, et al. Aortic valve replacement through right anterior minithoracotomy: can sutureless technology improve clinical outcomes? Ann Thorac Surg. 2014;98:1585-92.
6. Folliguet TA, Laborde F, Zannis K, Ghorayeb G, Haverich A, Shrestha M. Sutureless Perceval aortic valve replacement: results of two European centers. Ann Thorac Surg. 2012;93:1483-8.

7. Haverich A, Wahlers TC, Borger MA, Shrestha M, Kocher AA, Walther T, et al. Three-year hemodynamic performance, left ventricular mass regression, and prosthetic-patient mismatch after rapid deployment aortic valve replacement in 287 patients. J Thorac Cardiovasc Surg. 2014;148:2854-60.

8. Martens S, Sadowski J, Eckstein FS, Bartus K, Kapelak B, Sievers HH, et al. Clinical experience with the ATS $3 \mathrm{f}$ Enable(R) Sutureless Bioprosthesis. Eur J Cardiothorac Surg. 2011;40:749-55.

9. Kocher AA, Laufer G, Haverich A, Shrestha M, Walther T, Misfeld M, et al. One-year outcomes of the Surgical Treatment of Aortic Stenosis With a Next Generation Surgical Aortic Valve (TRITON) trial: a prospective multicenter study of rapid-deployment aortic valve replacement with the EDWARDS INTUITY Valve System. J Thorac Cardiovasc Surg. 2013;145: 110-6.

10. Akins CW, Miller DC, Turina MI, Kouchoukos NT, Blackstone EH, Grunkemeier GL, et al. Guidelines for reporting mortality and morbidity after cardiac valve interventions. Ann Thorac Surg. 2008;85:1490-5.

11. Borger MA, Moustafine V, Conradi L, Knosalla C, Richter M, Merk DR, et al. A randomized multicenter trial of minimally invasive rapid deployment versus conventional full sternotomy aortic valve replacement. Ann Thorac Surg. 2015; 99:17-25.

12. Bakir I, Casselman FP, Wellens F, Jeanmart H, De Geest R, Degrieck I, et al. Minimally invasive versus standard approach aortic valve replacement: a study in 506 patients. Ann Thorac Surg. 2006;81:1599-604.

13. Brinkman WT, Hoffman W, Dewey TM, Culica D, Prince SL, Herbert MA, et al. Aortic valve replacement surgery: comparison of outcomes in matched sternotomy and PORT ACCESS groups. Ann Thorac Surg. 2010;90:131-5.

14. Tabata M, Aranki SF, Fox JA, Couper GS, Cohn LH, Shekar PS. Minimally invasive aortic valve replacement in left ventricular dysfunction. Asian Cardiovasc Thorac Ann. 2007;15:225-8.

15. Bavaria JE, Desai ND, Cheung A, Petracek MR, Groh MA, Borger MA, et al. The St Jude Medical Trifecta aortic pericardial valve: results from a global, multicenter, prospective clinical study. J Thorac Cardiovasc Surg. 2014;147: 590-7.

16. Dalmau MJ, Gonzalez-Santos JM, Blazquez JA, Sastre JA, Lopez-Rodriguez J, Bueno M, et al. Hemodynamic performance of the Medtronic Mosaic and Perimount Magna aortic bioprostheses: five-year results of a prospectively randomized study. Eur J Cardiothorac Surg. 2011;39:844-52.

17. Dalmau MJ, Mariagonzalez-Santos J, Lopez-Rodriguez J, Bueno M, Arribas A. The Carpentier-Edwards Perimount Magna aortic xenograft: a new design with an improved hemodynamic performance. Interact Cardiovasc Thorac Surg. 2006;5:263-7.

18. McClure RS, Narayanasamy N, Wiegerinck E, Lipsitz S, Maloney A, Byrne JG, et al. Late outcomes for aortic valve replacement with the Carpentier-Edwards pericardial bioprosthesis: up to 17-year follow-up in 1,000 patients. Ann Thorac Surg. 2010;89:1410-6.

19. Cohn LH, Adams DH, Couper GS, Bichell DP, Rosborough DM, Sears SP, et al. Minimally invasive cardiac valve surgery improves patient satisfaction while reducing costs of cardiac valve replacement and repair. Ann Surg. 1997;226: 421-8.

20. Cosgrove DM III, Sabik JF. Minimally invasive approach for aortic valve operations. Ann Thorac Surg. 1996;62:596-7.

21. Tabata M, Umakanthan R, Cohn LH, Bolman RM III, Shekar PS, Chen FY, et al. Early and late outcomes of 1000 minimally invasive aortic valve operations. Eur J Cardiothorac Surg. 2008;33:537-41.

22. Dalen M, Biancari F, Rubino AS, Santarpino G, DePraetere H, Kasama K, et al. Ministernotomy versus full sternotomy aortic valve replacement with a sutureless bioprosthesis: a multicenter study. Ann Thorac Surg. 2015;99:524-30.

23. Nardi P, Pellegrino A, Scafuri A, Bellos, K, De Propris S, Polisca P, et al. Permanent pacemaker implantation after isolated aortic valve replacement: incidence, risk factors and surgical technical aspects. J Cardiovasc Med (Hagerstown). 2010;11:14-9.

24. Dawkins S, Hobson AR, Kalra PR, Tang AT, Monro JL, Dawkins KD. Permanent pacemaker implantation after isolated aortic valve replacement: incidence, indications, and predictors. Ann Thorac Surg. 2008;85:108-12.

25. Buellesfeld L, Stortecky S, Heg D, Hausen S, Mueller R, Wenaweser P, et al. Impact of permanent pacemaker implantation on clinical outcome among patients undergoing transcatheter aortic valve implantation. J Am Coll Cardiol. 2012;60:493-501. 
26. De Carlo M, Giannini C, Bedogni F, Klugmann S, Brambilla N, De Marco F, et al. Safety of a conservative strategy of permanent pacemaker implantation after transcatheter aortic CoreValve implantation. Am Heart J. 2012;163:492-9.

27. Mazine A. Conduction disorders following sutureless aortic valve replacement. Abstract presented at: American Association for Thoracic Surgery (AATS) Cardiovascular Valve Symposium, September 4-6, 2014, Istanbul, Turkey.

28. Rubino AS, Santarpino G, De Praetere H, Kasama K, Dalen M, Sartipy U, et al. Early and intermediate outcome after aortic valve replacement with a sutureless bioprosthesis: Results of a multicenter study. J Thorac Cardiovasc Surg. 2014; 148:865-71.

29. Baraki H, Al Ahmad A, Jeng-Singh S, Saito S, Schmitto JD, Fleischer B, et al. Pacemaker dependency after isolated aortic valve replacement: do conductance disorders recover over time? Interact Cardiovasc Thorac Surg. 2013:16:476-81.

30. Glauber M, Gilmanov D, Farneti PA, Kallushi E, Miceli A, Chiaramonti F, et al. Right anterior minithoracotomy for aortic valve replacement: 10-year experience of a single center. J Thorac Cardiovasc Surg. 2015;150:548-56.e2.

31. Malaisrie SC, Barnhart GR, Farivar RS, Mehall J, Hummel B, Rodriguez E, et al. Current era minimally invasive aortic valve replacement: techniques and practice. J Thorac Cardiovasc Surg. 2014;147:6-14.

32. Ghanta RK, Lapar DJ, Kern JA, Kron IL, Speir AM, Fonner E Jr, et al. Minimally invasive aortic valve replacement provides equivalent outcomes at reduced cost compared with conventional aortic valve replacement: a real-world multi-institutional analysis. J Thorac Cardiovasc Surg. 2015;149:1060-5.

33. Rodriguez E, Malaisrie SC, Mehall JR, Moore M, Salemi A, Ailawadi G, et al. Right anterior thoracotomy aortic valve replacement is associated with less cost than sternotomy-based approaches: a multi-institution analysis of 'real world' data. J Med Econ. 2014;17:846-52.

Key Words: aortic valve, bioprosthesis, heart valve, hemodynamics, replacement

\section{Discussion}

Dr S. Melby (St Louis, Mo). Congratulations on your excellent report of this new valve technology. My group currently operating at Barnes Jewish Hospital/Washington University in St Louis also has some experience with this valve and implantation technique. We found, similar to your report, that the implantation and crossclamp times can be shorter, especially after a short learning curve with the valve. However, there remain some questions about this new technology and specifically some questions about perivalvular leaks.

My first question is regarding your use of the valve and specifically your clinical use of this valve. Is there anyone in your group or involved in this study who has used the valve enough and thinks there are clinically significant improvements in the valve that give you the impetus to replace the currently used surgical valves with this new technology?
If there is someone using the valve clinically for that reason, what are the characteristics that make you think it is better? Is it the lower permanent pacemaker rate? Is it the shorter implantation times or the ability to use it through a smaller incision?

Dr Wahlers. That's a good point. There are several advantages for this type of valve. First, you can put in a valve, compared with other surgical valves, using a bigger size, about half or 1 size more.

The second point is perivalvular leak is not an entity as it was shown in the TRITON trial, and these data we have presented the last year at The American Association for Thoracic Surgery show that perivalvular leak rate was low, even lower compared with surgical valves.

As you also know, in Generation II, the skirt was modified to ensure an even better modeling of the left ventricular outflow tract. In the literature reported so far, there is no concern about perivalvular leak.

The combination of a proven valve design with this type of stent design will be effective in reducing the crossclamp times. This is a major advantage if you address even elderly people in the future. I think this is a good answer in the current transcatheter aortic valve implantation era, and I'm sure that if you can pay for the valve, implantation numbers will increase in the future compared with conventional surgical valves.

Dr Melby. My second question deals exactly with what you're talking about, the perivalvular leak you're describing. With this new technology, there still remains concern that this may be a weakness of this valve. In this study you presented, there were a few valves that needed to be repositioned and only 1 valve that had to be surgically explanted for perivalvular leak. Can you comment briefly on any of the techniques, or any of the concerns about the technique, that can help to prevent perivalvular leak or what the concerns for the long-term might be for perivalvular leak with this new technology?

Dr Wahlers. In general, I would say there is no concern for perivalvular leak if you apply the technique correctly. We all experience a type of learning curve, also because the design changed, and the valve has to be placed properly in the base. So exact measurement that has to be applied is important. But if you judge this correctly, I think there is no important risk of perivalvular leak in the future. 